\title{
Erratum to: Low-dose brachytherapy for early stage penile cancer: a 20-year single-institution study (73 patients)
}

Abel Cordoba*, Alexandre Escande, Stephanie Lopez, Laurent Mortier, Xavier Mirabel, Bernard Coche-Déqueant and Eric Lartigau

\section{Update and Erratum}

The original version of this article [1] has been updated to include the full names of the authors. No other changes have been made to the author list other than the inclusion of the author's first names.

Received: 6 September 2016 Accepted: 7 September 2016

Published online: 28 September 2016

\section{Reference}

1. Cordoba A, et al. Radiation Oncology. 2016;11:96. doi:10.1186/s13014-016-0676-9.

\footnotetext{
* Correspondence: a-cordoba@o-lambret.fr
}

Academic Radiation Oncology Department, Oscar Lambret Comprehensive

Cancer Center, SIRIC ONCOLille and University Lille 2, 3 rue Fréderic

Combemale, Lille, France 